\title{
HLA-B27 Misfolding and Ankylosing Spondylitis
}

\author{
Robert A. Colbert, Tri M. Tran, and Gerlinde Layh-Schmitt \\ Pediatric Translational Research Branch, National Institute of Arthritis and Musculoskeletal and \\ Skin Diseases, National Institutes of Health, Bethesda, MD, USA
}

\begin{abstract}
Understanding how HLA-B27 contributes to the pathogenesis of spondyloarthritis continues to be an important goal. Current efforts are aimed largely on three areas of investigation; peptide presentation to CD8 T cells, abnormal forms of the HLA-B27 heavy chain and their recognition by leukocyte immunoglobulin-like receptors on immune effector cells, and HLA-B27 heavy chain misfolding and intrinsic biological effects on affected cells. In this chapter we review our current understanding of the causes and consequences of HLA-B27 misfolding, which can be defined biochemically as a propensity to oligomerize and form complexes in the endoplasmic reticulum (ER) with the chaperone BiP (HSPA5/GRP78). HLA-B27 misfolding is linked to an unusual combination of polymorphisms that identify this allele, and cause the heavy chain to fold and load peptides inefficiently. Misfolding can result in ER-associated degradation (ERAD) of heavy chains, which is mediated in part by the E3 ubiquitin ligase HRD1 (SYVN1), and the ubiquitin conjugating enzyme UBE2JL. Upregulation of HLA-B27 and accumulation of misfolded heavy chains can activate ER stress signaling pathways that orchestrate the unfolded protein response. In transgenic rats where HLA-B27 is overexpressed, UPR activation is prominent. However, it is specific for heavy chain misfolding, since overexpression of HLA-B7, an allele that does not misfold, fails to generate ER stress. UPR activation has been linked to cytokine dysregulation, promoting IL-23, IFN $\beta$, and IL-1a production, and may activate the IL-23/IL-17 axis in these rats. IL-1 $\alpha$ and IFN $\beta$ are pro- and anti-osteoclastogenic cytokines, respectively, that modulate osteoclast development in HLA-B27-expressing transgenic rat monocytes. Translational studies of patient derived cells expressing HLA-B27 at physiologic levels have provided evidence that ER stress and UPR activation can occur in peripheral blood, but this has not been reported to date in isolated macrophages. Inflamed gastrointestinal tissue reveals evidence for HLA-B27 misfolding, ERAD, and autophagy, without acute UPR activation. A more complete picture of conditions that impact HLA-B27 folding and misfolding, the full spectrum and time course of consequences of ER stress, and critical cell types involved is needed to understand the role of HLA-B27 misfolding in spondyloarthritis pathogenesis.
\end{abstract}

\section{Keywords}

MHC class I; protein misfolding; endoplasmic reticulum stress; unfolded protein response; autophagy; ankylosing spondylitis; spondyloarthritis

\section{Introduction}

The group of diseases considered under the rubric of spondyloarthritis, affects around $1 \%$ of the population, and constitutes an important area of clinical, translational, and basic investigation in rheumatology (Dougados and Baeten, 2011; Helmick et al., 2008).

Corresponding author: Robert A. Colbert, MD, PhD, NIH/NIAMS, Bldg. 10/CRC, Rm. 1-5142, 10 Center Drive, MSC 1102, Bethesda, MD 20892, USA, Tele: +1 301443 8935, colbertr@mail.nih.gov. 
Ankylosing spondylitis, the prototypic form of spondyloarthritis, affects up to $0.5 \%$ of individuals in several populations, and is associated with the greatest disease burden. Despite considerable advances in treatment of ankylosing spondylitis with TNF inhibitors the goal of remission off medication remains elusive, and it is unclear whether structural damage can be slowed (Song and Maksymowych, 2012). Our understanding of genetic susceptibility to ankylosing spondylitis has grown immensely in the last several years with genome-wide association studies involving tens of thousands of patients and unaffected controls (Burton et al., 2007; Cortes et al., 2013; Evans et al., 2011; Reveille et al., 2010). What has emerged is a rich mixture of over two-dozen genes (or genomic regions) that together with HLA-B27 result in a chronic inflammatory disease with a predilection for the axial skeleton, entheseal inflammation, and altered bone homeostasis. Combined with translational and animal studies of pathogenesis, new pathways and potential targets have been implicated in ankylosing spondylitis and related diseases (Bowness et al., 2011; DeLay et al., 2009; Kenna et al., 2012; Layh-Schmitt and Colbert, 2008; Shen et al., 2009; Sherlock et al., 2012; Wendling et al., 2007). Despite these advances, our understanding of the most upstream molecular mechanisms that are likely to include effects of HLA-B27 in ankylosing spondylitis is far from complete (Colbert et al., 2010). Revealing these mechanisms continues to be an important goal as it offers the best chance to induce sustained remission and change disease outcome. The purpose of this review is to provide an update on our understanding of HLA-B27 misfolding in the context of other normal and abnormal features of this allele, and how this may contribute to our understanding of pathogenesis. We will consider known and potential consequences of misfolding, highlighting what has been learned from animal models as well as human studies.

\section{Unusual Features of HLA-B27}

There are three principle features of HLA-B27 that are known to distinguish it from other major histocompatibility complex (MHC) class I molecules. These include peptide binding specificity (Jardetzky et al., 1991; Madden et al., 1993), a tendency to misfold (Dangoria et al., 2002; Mear et al., 1999), and a predilection for forming heavy chain homodimers during cell surface recycling (Allen et al., 1999; Bird et al., 2003; Kollnberger et al., 2002). Each of these properties has been hypothesized independently to play a role in the pathogenesis of spondyloarthritis (Benjamin and Parham, 1990; Colbert, 2000; Edwards et al., 2000) (summarized in Figure 1). In the absence of definitive data to suggest otherwise, it is possible that more than one mechanism is involved. Although multiple mechanisms would seem to violate the principle that "plurality should not be posited without necessity" (Occam's Razor) a single explanation may not be adequate. Part of the difficulty in resolving these question relates to the fact that many of the polymorphisms that determine the unique peptide binding specificity also cause it to misfold and dimerize (Allen et al., 1999; Antoniou et al., 2004; Dangoria et al., 2002).

\section{HLA-B27 Misfolding \\ Historical Perspective}

The tendency of HLA-B27 to misfold was discovered serendipitously. Mutagenesis studies revealed that the $\mathrm{B}$ pocket in the peptide-binding groove conferred a slow folding phenotype that resulted in endoplasmic reticulum (ER)-associated degradation (ERAD) of a portion of newly synthesized heavy chains in transfected as well as EBV-transformed B cells with a single copy of HLA-B27, indicating that this was not an overexpression phenomenon (Mear et al., 1999). This occurred in transfected as well as EBV-transformed cells with a single copy of HLA-B27, indicating it was not an overexpression phenomenon. ERAD of other alleles was not found, and replacing the entire B pocket with residues from HLA-A2 corrected the abnormality, suggesting specificity and a possible relationship to peptide 
selection. Moreover, peptide-binding studies revealed a requirement for 30 -fold more peptide to induce proper folding of HLA-B27, due solely to the change in B pocket residues. Subsequent studies showed that newly synthesized HLA-B27 heavy chains oligomerized in disulfide-linked complexes, including dimer-sized structures whose formation was dependent on the unpaired cysteine at position $67\left(\mathrm{Cys}^{67}\right)$ (Dangoria et al., 2002). While these studies revealed that $\mathrm{Cys}^{67}$ could be involved in oligomerization, it was not sufficient alone for oligomerization, as mutations that induced rapid folding also prevented the formation of disulfide-linked complexes, even when $\mathrm{Cys}^{67}$ was present. Thus the relationship between individual amino acid residues and the abnormal behavior of HLA-B27 is complex, and cannot be inferred without expression and functional studies. Subsequent work has revealed that other unpaired Cys residues in HLA-B27 can contribute to the formation of disulfide-linked complexes (Fussell et al., 2008; Lenart et al., 2012). These studies used innovative methods that trap and modify cysteine residues in their native state, and thus enable visualization of unique structures after electrophoresis. This has revealed multiple species of oligomerized heavy chains, and more complexity than previously appreciated including intra- and inter-molecular disulfide-linked complexes. More work is needed to fully understand the aberrant behavior of HLA-B27.

ERAD of MHC class I was initially described for situations where misfolding was induced by heavy chain expression in the absence of $\beta_{2} \mathrm{~m}$, or when the peptide supply to the ER was dramatically limited by genetic deletion of peptide transporter subunits (Hughes et al., 1997). ERAD involves deglycosylation and dislocation of the heavy chain from the ER into the cytosol, with subsequent ubiquitination and proteasome-mediated degradation. Recent studies have shown that ubiquitination requires the E3 ubiquitin ligase HRD1 (SYVN1 or synoviolin), and the E2 ubiquitin conjugating enzyme UBE2J1 (Burr et al., 2011). Interestingly, in the absence of HRD1 misfolded HLA-B27 oligomers accumulated in HeLa cells, even in the presence of an intact class I assembly pathway, providing further evidence for HLA-B27 misfolding and demonstrating that ERAD is important for the clearance of these aberrant complexes (Burr et al., 2011). These studies raise the possibility that overexpression of HRD1 and/or UBE2J1 might prevent the accumulation of HLA-B27 oligomers. However, it should be noted that widespread HRD1 overexpression in mice can have detrimental consequences, including the development of arthropathy (Amano et al., 2003).

The ER chaperone BiP (HSPA5/GRP78) binds transiently to many ER-synthesized proteins, including MHC class I heavy chains (Noessner and Parham, 1995). In contrast, newly synthesized HLA-B27 heavy chains exhibit a prolonged association with BiP, and stable complexes can be readily purified at steady state from transfected cells expressing HLA-B27 using the HC10 antibody (Colbert et al., 2010). HC10 recognizes a subset of HLA-B and C heavy chains before they completely fold (pre-folded) and associate with $\beta_{2} \mathrm{~m}$ (Stam et al., 1986), as well as unfolded heavy chains that have lost $\beta_{2} \mathrm{~m}$ and peptide. It also recognizes HLA-B27 oligomers and dimers that are considered misfolded (see below) (Dangoria et al., 2002). In contrast, HLA-B27 complexes purified using the antibody W6/32 contain $\beta_{2} \mathrm{~m}$ and exhibit no association with $\mathrm{BiP}$. BiP has been shown to bind predominantly to oligomers of HLA-B27 in cells from HLA-B27/human $\beta_{2} \mathrm{~m}\left(\mathrm{~h} \beta_{2} \mathrm{~m}\right)$ transgenic rats (Tran et al., 2004). Since BiP binds transiently to class I heavy chains that do not dimerize, it seems likely that binding to HLA-B27 would precede dimerization. BiP binds to exposed hydrophobic regions of proteins to prevent self-association, but is found associated with disulfide-bonded aggregates of other proteins that misfold (Molinari et al., 2002; Molinari et al., 2005). It might remain bound to HLA-B27 as a consequence of oligomerization. The biochemical details of these processes for HLA-B27 have not been elucidated. 


\section{Influence of HLA Class I Assembly Pathway Components}

Although misfolding of HLA-B27 might imply the formation of specific structures such as dimers, our current definition is primarily functional. Evidence of misfolding is based on oligomerization, prolonged BiP binding and ER accumulation of heavy chains, together with evidence of ERAD. For certain proteins that misfold, ERAD is so efficient that the aberrant protein does not accumulate, and thus the consequences of misfolding are due to loss of the functional gene product. It should be noted that when HLA-B27 is expressed in cells depleted of ER peptides due to TAP transporter deficiency, oligomers are not readily observed despite significant accumulation of unfolded heavy chains (Dangoria et al., 2002), suggesting that peptides are required for HLA-B27 oligomerization. This is of particular importance given evidence that polymorphisms in intracellular peptidases that can influence the quality and quantity of peptides available for presentation by HLA class I molecules affect susceptibility to ankylosing spondylitis (Cortes et al., 2013; Evans et al., 2011). Interestingly, the genetic effect of ERAP1 (ER aminopeptidase-1), which trims peptides in the ER, is limited to HLA-B27 positive individuals (Evans et al., 2011), while ERAP2 and/ or LNPEP (leucyl/cystinyl aminopeptidase), and possibly NPEPPS (puromycin sensitive aminopeptidase) variants appear to be independently associated with disease (Cortes et al., 2013). These observations, together with the effects of peptide supply on HLA-B27 misfolding, suggest a complex relationship that will need to be elucidated with careful investigations.

\section{Consequences of Protein Misfolding in the ER}

Protein misfolding has a variety of biological effects depending on the nature and quantity of the protein that misfolds, the severity of the defect, where the protein is synthesized, the sufficiency of quality control processes, and how cells or tissues respond to the accumulation of aberrant proteins. Our understanding of protein quality control and its complexity has grown tremendously, and with it an appreciation for the importance of protein misfolding and its consequences for the pathogenesis of a number of diseases. For interested readers, Gregersen and Bross recently provided a comprehensive overview of the cellular response to protein misfolding, highlighting the cytosolic, mitochondrial, and endoplasmic reticulum compartmentalization of protein quality control and unfolded protein responses (Gregersen and Bross, 2010). The ER is the major cellular compartment where secreted and membrane bound proteins are synthesized and folded, and in some cases such as MHC class I heavy chains, where they are loaded with cargo. For the purposes of this review we will focus our attention on the ER.

The accumulation of misfolded or even unfolded proteins can perturb ER function resulting in ER stress (summarized in Figure 2). Quality control processes such as ERAD may be able to prevent the accumulation of misfolded proteins and thus circumvent an ER stress response (Ellgaard and Helenius, 2003). However, whether or not a misfolded protein is efficiently and completely degraded by ERAD depends on a host of factors that remain incompletely understood. In recent years it has become apparent that autophagy also plays an important role in maintaining ER homeostasis and is part of a larger 'integrated stress response' (Kroemer et al., 2010). Autophagy is a conserved and tightly regulated pathway whereby cellular contents can be sequestered and targeted for lysosomal degradation (Kundu and Thompson, 2008). Autophagy can dispose of cellular components either in a nonspecific (bulk autophagy, or simply autophagy) or specific fashion (chaperone-mediated autophagy). Basal levels of autophagy occur in most cells, and this pathway can be dramatically upregulated during cellular differentiation or by a number of stimuli including nutrient deprivation, accumulation of misfolded proteins or protein aggregation, and is also important for sequestration and elimination of intracellular microbes. Autophagy can be activated by ER stress through at least two signal transducers. Eukaryotic initiation 
factor-2a (eIF2a) kinase (PERK, encoded by EIF2AK3) activation can lead to transcriptional induction of key autophagy genes, LC3 and ATG5 particularly under hypoxic conditions (Rouschop et al., 2010). This is mediated by PERK-induced eIF2a phosphorylation, which results in translational induction of ATF4 and CHOP transcription factors that induce autophagy genes. Interestingly, X-box binding protein-1 (XBP1) has been reported to be a negative regulator of autophagy (Hetz et al., 2009). In the absence of XBP1, basal autophagy is increased which enhances the turnover of mutant SOD-1 in an animal model of amyotrophic lateral sclerosis, thereby increasing resistance to disease (Hetz et al., 2009). More recent studies have implicated the protein product of the unspliced XBP1 mRNA (XBP1u) in this process, since it can control the turnover of FOXO1, a key transcription factor that upregulates autophagy genes and can also activate ATG7 and autophagy through direct binding (Vidal and Hetz, 2013; Zhao et al., 2013). XBP1u can bind to activated FOXO1, targeting it for proteasomal degradation, and thus limiting basal autophagy. Therefore, lower levels of XBP1u due to a gene deletion, or possibly due to Inositol requiring-1 (IRE1)-mediated splicing of XBP1u during acute ER stress could reduce levels of XBP1u protein and activate autophagy. However, IRE1 activation can increase autophagy through JNK1 (Jun N-terminal kinase-1) phosphorylation (Ogata et al., 2006). Since the dominant effect of acute ER stress is to activate autophagy, the role of XBP1u may come later. Since ER stress can upregulate XBP1u expression, XBP1u may be more important in later stages dampening the autophagic response to ER stress (Kroemer et al., 2010).

\section{Consequences of HLA-B27 Misfolding}

Our current understanding of many of the consequences of HLA-B27 misfolding, derive from experiments using transgenic rats. Consequently we will briefly review key aspects of this animal model.

\section{HLA-B27 Transgenic Rats}

There are currently two animal models of HLA-B27-associated disease in rats (Hammer et al., 1990; Tran et al., 2006). In 1990, Taurog and colleagues demonstrated that overexpression of HLA-B27 together with $\mathrm{h} \beta_{2}$ m could induce 'spontaneous' spondyloarthritis-like disease, with inflammatory bowel disease in virtually $100 \%$ of rats, but a lower frequency of peripheral and minimal axial arthritis (Taurog et al., 1999) (SpA-1) (Figure 3). In SpA-1, disease occurs in rats with 40 copies of the HLA-B27 transgene together with 30 copies of $\mathrm{h} \beta_{2} \mathrm{~m}$, but not 20 copies of HLA-B27 and 15 copies of $\mathrm{h} \beta_{2} \mathrm{~m}$ (Taurog et al., 1993). HLA-B27 heavy chain (and $\mathrm{h} \beta_{2} \mathrm{~m}$ ) expression is greater with higher transgene copy number, indicating a critical threshold produced between 20 and 40 copies. However, it is important to note that comparable overexpression of the HLA-B7 heavy chain in rats (from 52 copies of HLA-B7 and 10 copies of $\mathrm{h} \beta_{2} \mathrm{~m}$ ) does not cause disease (Taurog et al., 1999), and thus non-specific overexpression of an HLA class I allele is not sufficient.

The second rat model of spondyloarthritis (SpA-2) occurs with 20 as well as 55 copies of HLA-B27, but requires greater overexpression of $\mathrm{h} \beta_{2} \mathrm{~m}$ from an additional 35 copies of this transgene (Tran et al., 2006). Interestingly, in SpA-2, rats with 20 copies of HLA-B27 are not affected with IBD or arthritis, but the extra $\mathrm{h} \beta_{2} \mathrm{~m}$ causes more frequent and severe arthritis and spondylitis, better resembling ankylosing spondylitis (Figure 3). It remains unclear how the additional $\mathrm{h} \beta_{2} \mathrm{~m}$ causes arthritis and spondyloarthritis. It reduces free heavy chain expression on the cell surface of PBMC (peripheral blood mononuclear cell) subpopulations without increasing levels of folded HLA-B27. The extra $\mathrm{h} \beta_{2} \mathrm{~m}$ promotes HLA-B27 folding and reduces oligomerization, but it does not eliminate it (see below). In transgenic rats with 55 copies of HLA-B27, IBD is not changed by the additional $\mathrm{h} \beta_{2} \mathrm{~m}$, yet arthritis and spondylitis are more frequent and more severe (Tran et al., 2006). Whether the 
affect of extra $\mathrm{h} \beta_{2} \mathrm{~m}$ on the spondyloarthritis phenotype is exerted through HLA-B27 or independently is not clear. It is possible that the additional $\mathrm{h} \beta_{2} \mathrm{~m}$ induces biological effects on cells such as fibroblasts and macrophages (Hou et al., 2001; Miyata et al., 1996; Schmidt et al., 2001). Since $\mathrm{h} \beta_{2} \mathrm{~m}$ overexpression in the absence of HLA-B27 does not cause disease, any off-target effect must still require a biological effect of HLA-B27.

The ability of HLA-B27 to cause spondyloarthritis in a high percentage of transgenic rats in the absence of any other known predisposing genes is quite remarkable given the situation in humans, where 95-99\% of HLA-B27 positive individuals remain healthy (Reveille, 2012). It could be that HLA-B27 overexpression overcomes the need for additional susceptibility alleles, and promotes the highly penetrant phenotype. There is evidence that homozygosity for HLA-B27 carries an increased risk for developing ankylosing spondylitis (Jaakkola et al., 2006), and that increased HLA-B27 expression in human PBMCs is associated with disease (Cauli et al., 2002; Cauli et al., 2012). Copy number variation at the HLA-B locus in humans has not been reported or to our knowledge examined in ankylosing spondylitis. It would be interesting to examine low copy number HLA-B27 transgenic rats with genetic modifications that mimic other ankylosing spondylitis susceptibility alleles to see if this promotes disease.

\section{HLA-B27-Induced UPR Activation}

In early studies of HLA-B27 misfolding in transgenic rats, we focused on the question of whether there was sufficient misfolding to generate ER stress and activate the UPR. This was apparent in bone marrow macrophages from rats with established disease, but in young healthy animals, UPR activation only became apparent during upregulation of HLA-B27 (Turner et al., 2007; Turner et al., 2005). We established a strong correlation between the magnitude of HLA-B27 induction by interferons (IFN) and TNFa and upregulation of the ER chaperone, BiP (Turner et al., 2007). Induction of HLA-B27 led to increased formation of disulfide-linked HLA-B27 oligomers and a large increase in the accumulation of BiPbound heavy chains indicating exacerbated misfolding. To determine whether UPR activation simply reflected the overexpression of an HLA class I heavy chain, we compared HLA-B7 transgenic rats with a similar HLA-B transgene copy number (52 vs. 55 for HLAB27). HLA-B7 overexpression and upregulation fails to activate ER stress signaling pathways despite levels of HLA class I heavy chain expression comparable to HLA-B27. Moreover, we find no evidence of HLA-B7 oligomerization or BiP binding (Colbert et al., 2010; Turner et al., 2007). It is also notable that the ratio of unfolded to folded heavy chains at steady state and after upregulation with IFN $\gamma$ is considerably higher for HLA-B27 than for HLA-B7.

\section{HLA-B27 Misfolding and ER Stress in Low Copy Number Rats}

The discovery that additional $\mathrm{h}{ }_{2}$ m expression could alter the phenotype of HLA-B27 transgenic rats raised the important question of whether misfolding and UPR activation were affected, and ultimately whether this experiment could inform the relationship between these phenomena and disease (Tran et al., 2006). Additional $\mathrm{h} \beta_{2} \mathrm{~m}$ overexpression promoted HLAB27 folding as evidenced by more rapid conversion of unfolded heavy chains to folded trimolecular complexes (Tran et al., 2006), and attenuated but did not eliminate oligomerization. When lectin (con-A)-activated splenocytes were examined, additional $\mathrm{h} \beta_{2} \mathrm{~m}$ overexpression was associated with a reduction in BiP mRNA levels of approximately $25 \%$, with relative expression being reduced to a level seen in non-transgenic or HLA-B7 transgenic rats. This led to the suggestion that UPR triggering, although potentially important for colitis, was unlikely to be involved in the arthritis component of disease. However, subsequent studies examining macrophages from these rats and under conditions of HLA-B27 upregulation, revealed that UPR activation is still quite robust, and only 
diminished in magnitude by additional $\mathrm{h} \beta_{2} \mathrm{~m}$ (Colbert et al., 2010). Enhanced cytokine expression as a consequence of UPR activation was still present (discussed below). Con-Aactivated splenocytes do not exhibit substantial upregulation of HLA-B27 or activation of the UPR, even from high copy number rats (Turner et al., 2007). These results underscore the importance of understanding how HLA-B27 expression and ER stress affect different cell types, including those most directly linked to disease pathogenesis. In addition, UPR activation may be a double-edged sword. Strong and unmitigated UPR activation, while having the potential to be strongly pro-inflammatory in one context, might lead to premature apoptotic cell death thus limiting inflammation and having a beneficial effect in another context. We also know little about effects of chronic protein misfolding and adaptation, which might be reflected in differences in baseline BiP expression that alter the responsiveness of cells to further stressors.

\section{UPR and Cytokine Regulation}

Several studies have revealed convergence between UPR signaling pathways and cytokine regulatory networks. XBP1 is synthesized from the spliced form of the XBP1 mRNA $(X B P 1 s)$, which is generated by IRE1a (encoded by ERN1) following ER stress activation. In addition to functioning as a transcriptional promoter for many UPR target genes including those in the ERAD pathway, XBP1s can bind to a downstream enhancer in IfnbI and promote transcription and IFN $\beta$ production following ER stress (Smith et al., 2008b; Zeng et al., 2010). The effect on IFN $\beta$ production is small unless other stimulators of the Ifnbl gene such as TLR3/TLR4 agonists are present, whereupon synergistic induction is seen (Smith et al., 2008b). Martinon and colleagues have shown that IRE1a/XBP1 play a role in TLRmediated regulation of IL-6 and TNFa (Martinon et al., 2010). In particular, after several hours of treatment with TLR4 or TLR2 agonists, IRE1a activation and XBP1 splicing were seen without PERK or activating transcription factor-6 (ATF6) activation, indicating that a full UPR was not activated. The TLR-mediated IRE1 $a$ activation was dependent on the NOX2 NADPH oxidase together with TRAF6 and required production of reactive oxygen species (ROS). In these studies XBP1 was shown to be critical for full IL-6, TNFa, and IFN $\beta$ induction by TLR agonists. Thus XBP1 is important for normal expression of these cytokines during an immune response, and can contribute to synergistic induction during ER stress.

IL-23 production is also influenced by UPR activation (DeLay et al., 2009). There is substantial synergistic induction of IL-23p19 mRNA and production of active cytokine in TLR3/TLR4-treated macrophages experiencing ER stress induced either by pharmacologic agents or by HLA-B27 upregulation (Colbert et al., 2010; DeLay et al., 2009). The UPR effect on IL-23 is mediated by CHOP (C/EBP homologous protein 10, DDIT3), which is induced via PERK activation, and binds to the IL23A promoter (Goodall et al., 2010). The recent discovery that IL-23 receptor (IL23R) expressing T cells reside in the entheses, and when triggered by systemic IL-23 can produce spondyloarthritis, provides unique insights into how this phenotype may develop in humans (Sherlock et al., 2012). These T cells are unusual in that they resemble Th17 T cells but are CD4/CD8 negative (IL23R+/ROR- $\gamma \mathrm{t}+$ / Sca1+/CD3+/CD8-/CD4-). They are covered in another chapter of this issue, and thus we will not elaborate on their potential importance here, except to point out that this discovery provides evidence contrary to the notion that tissue specific antigen presentation is a prerequisite for development of spondyloarthritis.

We recently found that bone marrow derived monocytes from HLA-B27 transgenic rats produce more IL-1a as well as IFN $\beta$ when ER stress is induced by TNFa-mediated upregulation of HLA-B27 (Layh-Schmitt et al., 2013). This was discovered when we observed that HLA-B27 expression promoted TNFa-induced osteoclast development from 
transgenic bone marrow monocytes, an effect that could be completely blocked with antiIL-1a neutralizing antibodies. Interestingly, we found that blocking IFN $\beta$ resulted in an even greater increase in TNFa-driven osteoclast formation. IFN $\beta$ is known to antagonize proosteoclastogenic effects of RANKL (receptor activator of NF-kB ligand) by autocrine inhibition of RANKL-induced c-Fos expression (Takayanagi et al., 2002). This feedback inhibitory loop plays an important role in regulation of osteoclast formation and bone destruction during inflammation. We found no effect of HLA-B27 on RANKL-stimulated osteoclastogenesis, consistent with the failure of RANKL to induce HLA-B27 expression, accumulation of misfolded oligomers, and UPR activation. Furthermore, HLA-B7 had no effect on TNFa-driven osteoclastogenesis, consistent with lack of ER stress in cells expressing this allele. Our studies demonstrate that IFN $\beta$ can play a role in TNFa-mediated osteoclastogenesis in the context of HLA-B27 misfolding and ER stress-mediated pathogenic mechanisms. Whether physiological levels of TNFa-induced IFN $\beta$ (Yarilina et al., 2008) inhibit osteoclastogenesis has not to our knowledge been examined. The demonstration that HLA-B27 expression can promote the production of both pro- and antiosteoclastogenic cytokines is intriguing given the bone phenotype of ankylosing spondylitis where bone loss and abnormal formation can occur in close proximity in vertebral bodies.

Together these studies demonstrate interesting and unexpected convergence of signaling pathways and suggest that ER stress and its consequences may contribute to low-grade tissue inflammation that is further enhanced by innate immune signaling through TLR pathways. In addition, generation of ER stress in HLA-B27-expressing cells exposed to TNFa and IFNs may alter the cellular response to these cytokines and change the biological outcome in ways that are relevant to disease pathogenesis. This latter concept has implications for how we think about HLA-B27 and disease. For example, cell intrinsic effects of HLA-B27 that alter osteoclast development or possibly osteoblast function would be considered downstream in pathogenesis, yet play a critical in the alteration of bone homeostasis. These effects of HLA-B27 may not be pro-inflammatory, but rather serve to modulate the response to pro-inflammatory signals.

\section{Cell Type Dependence}

HLA class I molecules are nearly ubiquitously expressed, and thus misfolding of an HLA-B allele has the potential to affect a variety of cell types. However, cell types differ in their basal and inducible expression of HLA class I, and in their ability to handle misfolded proteins, so biological effects can vary or be limited. For example, splenocytes (primarily $\mathrm{T}$ and B lymphocytes) from HLA-B27 transgenic rats accumulate significant amounts of HLA-B27 heavy chain monomers and disulfide-linked oligomers, yet exhibit little increase in HLA-B27 expression when treated with IFN $\gamma(<2$-fold), and no significant upregulation of $\mathrm{BiP}$ or activation of XBP1 splicing (Turner et al., 2007). Prior to cytokine treatment, splenocytes expressing HLA-B27 have about 2-fold higher levels of BiP mRNA, and exhibit low levels of ongoing XBP1 splicing (2-3\%) that are higher than non-transgenic cells, suggesting low level UPR activation and/or adaptation to misfolded heavy chain expression.

Our recent studies on osteoclast development in HLA-B27 transgenic rats have revealed that bone marrow monocytes are affected by HLA-B27 misfolding (Layh-Schmitt et al., 2013), and similar effects can be seen in osteoblasts (unpublished observations). Other potentially disease-relevant cells that need to be examined include mesenchymal and hematopoietic stem cells and lineage progenitors, T/B/NK cells, and even fibroblasts. Although finding effects in monocytes as well as macrophages (Smith et al., 2008b; Turner et al., 2007; Turner et al., 2005) may not seem surprising, macrophages may be better suited to handle misfolded proteins. Dickhout and colleagues have shown that monocyte to macrophage differentiation is associated with UPR activation, which conferred cytoprotection from further exposure to ER stress inducing agents (Dickhout et al., 2011). 


\section{HLA-B27 Expression. Misfolding, and ER Stress in Human Cells and Tissues}

Early studies of adherent synovial fluid macrophages from spondyloarthritis patients compared to similar cells from individuals with rheumatoid arthritis showed greater expression of BiP mRNA, suggesting the presence of a UPR (Gu et al., 2002). This observation was confirmed and extended by Dong et al., who reported greater BiP protein expression in macrophages from peripheral joints of subjects with ankylosing spondylitis compared to osteoarthritis (Dong et al., 2008). There was also a correlation between synovial fluid cytokines TNFa and IL-6 and macrophage BiP expression, and between serum IL-6, disease activity and macrophage BiP (Dong et al., 2008). We wanted to address the question of whether IFN $\gamma$ upregulation of HLA-B27 would activate the UPR in macrophages from HLA-B27-positive ankylosing spondylitis subjects. To do this we cultured peripheral blood monocytes in GM-CSF for 6-7 days to derive macrophages, but found no significant upregulation of HLA-B transcripts with IFN $\gamma$, nor did we see evidence of UPR activation (Smith et al., 2008a). Subsequent studies by Zeng et al. using M-CSFderived macrophages obtained approximately 2-fold upregulation of HLA-B with IFN $\gamma$ that did not activate the UPR (Zeng et al., 2011). In contrast, unfractionated PBMC from patients with active ankylosing spondylitis and reactive arthritis have revealed evidence for UPR activation in HLA-B27 positive subjects, and with IFN $\gamma$ treatment (Feng et al., 2012). One study examining dendritic cells (DCs) derived from peripheral blood monocytes using IL-4 and GM-CSF over 5 days, followed by LPS maturation for 3 days, showed HLA class I dimer formation in controls lacking HLA-B27 as well as in HLA-B27 positive patients (Campbell et al., 2011). Although dimers were HC10 reactive, it was not clear whether they were intracellular or located on the cell surface. BiP mRNA expression and XBP1 mRNA splicing were unchanged at the end of the experiment, and thus there was no evidence for ER stress occurring in either group. The absence of $X B P 1$ splicing was unexpected since the gene is required for DC maturation, and constitutive splicing has been noted in immature DCs (Iwakoshi et al., 2007). It will be important to determine whether monocytes and immature or mature DCs respond to cytokines and HLA-B upregulation similarly to PBMC. It is clear that additional studies are needed to confirm UPR activation in PBMC from ankylosing spondylitis patients, to define the cells that are exhibiting ER stress, and to establish whether HLA-B27 is mediating this process.

Inflammatory gut lesions are present in up to $70 \%$ of ankylosing spondylitis patients (Jacques et al., 2012), while an estimated 5-6\% of patients have co-existing inflammatory bowel disease. Recently Ciccia and colleagues have extensively evaluated the immunology of subclinical inflammatory gut lesions in patients with ankylosing spondylitis. They discovered that IL-23p19 is overexpressed in ileal tissue from ankylosing spondylitis patients with chronic lesions, similar to individuals with Crohn's disease (Ciccia et al., 2009). However, ankylosing spondylitis patients lacked significant IL-17A upregulation or other downstream or Th1 cytokines that were seen in Crohn's disease patients. Ankylosing spondylitis patients exhibited increased IL-22 expression, and IL-22-producing NKp44 NK cells that were hypothesized to be protective (Ciccia et al., 2012). More recently, potential mechanisms for IL-23 overproduction were examined (Ciccia et al., 2013). Increased expression of XBP1u was noted in chronic lesions from ankylosing spondylitis patients, but other markers of an acute UPR such as BiP (HSPA5), protein disulfide isomerase-4 (PDIA4), or XBP1s were not elevated. However, there was strong evidence for activation of the autophagy pathway in mononuclear cells in chronic lesions from ankylosing spondylitis patients similar to Crohn's disease. Unfolded or misfolded HLA-B heavy chains recognized by the $\mathrm{HC} 10$ antibody were prominent in ankylosing spondylitis patients with chronic inflammation, where increased staining for HRD1 (SYVN1) was also noted. Indeed, a striking number of cells co-stained with HC10 and HRD1 in ankylosing spondylitis patients but not Crohn's disease or healthy controls. Moreover, folded heavy chains stained with 
W6/32 did not localize with HRD1. These studies are consistent with the possibility that unfolded/misfolded HLA-B27 heavy chains may be accumulating in inflammatory gut lesions of ankylosing spondylitis patients despite active ERAD. This might be linked to activation of autophagy pathways as a mechanism to clear heavy chain aggregates either without activating the UPR, or after transient UPR activation in affected cells. Blocked autophagy has been shown to increase IL-23 expression and secretion from dendritic cells (Peral de Castro et al., 2012). However, the lack of SQSTM1 (sequestosome-1) accumulation argued against this occurring in gut tissue. These important observations need to be extended to better define the role of HLA-B27, and to establish whether autophagy is activated in other cells and tissues, and ultimately whether this is related to the misfolding and oligomerization of HLA-B27.

In our experience studying HLA-B27 transgenic rat cells, UPR activation is most readily apparent when baseline expression of HLA-B27 begins low and is then maximally upregulated. Some of the most prominent changes in expression are observed in cells derived from the bone marrow, which is a difficult tissue to obtain routinely from research subjects. In addition, the UPR is indeed a 'response' - a time dependent process that decays over time particularly when ER stress is mild and can be resolved. This needs to be taken into account when looking for evidence of UPR activation in cells and tissues.

\section{Conclusions and Future Considerations}

The evidence that HLA-B27 misfolds and can generate ER stress has many implications for spondyloarthritis and ankylosing spondylitis pathogenesis. The altered response of cells exhibiting UPR activation to innate immune stimuli can alter cytokine production. Conceptually, the UPR or subsequent consequences like autophagy may act as additional signals promoting production of certain pro-inflammatory cytokines such as IL-23, and thus be situated upstream in pathogenesis. However, consequences of HLA-B27 misfolding during the response to cytokines including TNFa and IFN $\gamma$ may play a more important downstream role that contributes to the unique spondyloarthritis phenotype. Consequences of HLA-B27 misfolding are prominent in transgenic rats where greater expression and upregulation can be readily achieved. In human cells and tissues evidence for HLA-B27 misfolding and its consequences is accumulating, but not surprisingly effects are more subtle and the spectrum of involved cells and tissues may be different. More work is needed to better define the types of cells and conditions that elicit these responses. While UPR activation is an important consequence of ER stress, it is not the only one. We need to better understand the relationship between HLA-B27 misfolding, HRD1 overexpression and ERAD, and activation of autophagy as a potential consequence of ER stress or the response to other microbial stimuli.

\section{References}

Allen RL, O'Callaghan CA, McMichael AJ, Bowness P. Cutting edge: HLA-B27 can form a novel beta 2-microglobulin-free heavy chain homodimer structure. J Immunol. 1999; 162:5045-5048. [PubMed: 10227970]

Amano T, Yamasaki S, Yagishita N, Tsuchimochi K, Shin H, Kawahara K, Aratani S, Fujita H, Zhang L, Ikeda R, et al. Synoviolin/Hrd1, an E3 ubiquitin ligase, as a novel pathogenic factor for arthropathy. Genes \& development. 2003; 17:2436-2449. [PubMed: 12975321]

Antoniou AN, Ford S, Taurog JD, Butcher GW, Powis SJ. Formation of HLA-B27 homodimers and their relationship to assembly kinetics. J Biol Chem. 2004; 279:8895-8902. [PubMed: 14684742]

Benjamin RJ, Parham P. Guilt by association: HLA-B27 and ankylosing spondylitis. Immunol Today. 1990; 11:137-142. [PubMed: 2187471] 
Bird LA, Peh CA, Kollnberger S, Elliott T, McMichael AJ, Bowness P. Lymphoblastoid cells express HLA-B27 homodimers both intracellularly and at the cell surface following endosomal recycling. Eur J Immunol. 2003; 33:748-759. [PubMed: 12616495]

Bowness P, Ridley A, Shaw J, Chan AT, Wong-Baeza I, Fleming M, Cummings F, McMichael A, Kollnberger S. Th17 cells expressing KIR3DL2+ and responsive to HLA-B27 homodimers are increased in ankylosing spondylitis. J Immunol. 2011; 186:2672-2680. [PubMed: 21248258]

Burr ML, Cano F, Svobodova S, Boyle LH, Boname JM, Lehner PJ. HRD1 and UBE2J1 target misfolded MHC class I heavy chains for endoplasmic reticulum-associated degradation. Proc Natl Acad Sci U S A. 2011; 108:2034-2039. [PubMed: 21245296]

Burton PR, Clayton DG, Cardon LR, Craddock N, Deloukas P, Duncanson A, Kwiatkowski DP, McCarthy MI, Ouwehand WH, Samani NJ, et al. Association scan of 14,500 nonsynonymous SNPs in four diseases identifies autoimmunity variants. Nat Genet. 2007; 39:1329-1337. [PubMed: 17952073]

Campbell EC, Fettke F, Bhat S, Morley KD, Powis SJ. Expression of MHC class I dimers and ERAP1 in an ankylosing spondylitis patient cohort. Immunology. 2011; 133:379-385. [PubMed: 21574996]

Cauli A, Dessole G, Fiorillo MT, Vacca A, Mameli A, Bitti P, Passiu G, Sorrentino R, Mathieu A. Increased level of HLA-B27 expression in ankylosing spondylitis patients compared with healthy HLA-B27-positive subjects: a possible further susceptibility factor for the development of disease. Rheumatology (Oxford). 2002; 41:1375-1379. [PubMed: 12468816]

Cauli A, Dessole G, Vacca A, Porru G, Cappai L, Piga M, Bitti PP, Fiorillo MT, Sorrentino R, Carcassi C, et al. Susceptibility to ankylosing spondylitis but not disease outcome is influenced by the level of HLA-B27 expression, which shows moderate variability over time. Scand J Rheumatol. 2012; 41:214-218. [PubMed: 22360441]

Ciccia F, Accardo-Palumbo A, Alessandro R, Rizzo A, Principe S, Peralta S, Raiata F, Giardina A, De Leo G, Triolo G. Interleukin-22 and interleukin-22-producing NKp44+ natural killer cells in subclinical gut inflammation in ankylosing spondylitis. Arthritis Rheum. 2012; 64:1869-1878. [PubMed: 22213179]

Ciccia F, Accardo-Palumbo A, Rizzo A, Guggino G, Raimondo S, Giardina A, Cannizzaro A, Colbert RA, Alessandro R, Triolo G. Evidence that autophagy, but not the unfolded protein response, regulates the expression of IL-23 in the gut of patients with ankylosing spondylitis and subclinical gut inflammation. Ann Rheum Dis. 2013

Ciccia F, Bombardieri M, Principato A, Giardina A, Tripodo C, Porcasi R, Peralta S, Franco V, Giardina E, Craxi A, et al. Overexpression of interleukin-23, but not interleukin-17, as an immunologic signature of subclinical intestinal inflammation in ankylosing spondylitis. Arthritis Rheum. 2009; 60:955-965. [PubMed: 19333939]

Colbert RA. HLA-B27 misfolding: A solution to the spondyloarthropathy conundrum? Mol Med Today. 2000; 6:224-230. [PubMed: 10840380]

Colbert RA, DeLay ML, Klenk EI, Layh-Schmitt G. From HLA-B27 to spondyloarthritis: a journey through the ER. Immunol Rev. 2010; 233:181-202. [PubMed: 20193000]

Cortes A, Hadler J, Pointon JP, Robinson PC, Karaderi T, Leo P, Cremin K, Pryce K, Harris J, Lee S, et al. Identification of multiple risk variants for ankylosing spondylitis through high-density genotyping of immune-related loci. Nat Genet. 2013

Dangoria NS, DeLay ML, Kingsbury DJ, Mear JP, Uchanska-Ziegler B, Ziegler A, Colbert RA. HLAB27 misfolding is associated with aberrant intermolecular disulfide bond formation (dimerization) in the endoplasmic reticulum. J Biol Chem. 2002; 277:23459-23468. [PubMed: 11978783]

DeLay ML, Turner MJ, Klenk EI, Smith JA, Sowders DP, Colbert RA. HLA-B27 misfolding and the unfolded protein response augment interleukin-23 production and are associated with Th17 activation in transgenic rats. Arthritis Rheum. 2009; 60:2633-2643. [PubMed: 19714651]

Dickhout JG, Lhotak S, Hilditch BA, Basseri S, Colgan SM, Lynn EG, Carlisle RE, Zhou J, Sood SK, Ingram AJ, et al. Induction of the unfolded protein response after monocyte to macrophage differentiation augments cell survival in early atherosclerotic lesions. Faseb J. 2011; 25:576-589. [PubMed: 20966213] 
Dong W, Zhang Y, Yan M, Liu H, Chen Z, Zhu P. Upregulation of 78-kDa glucose-regulated protein in macrophages in peripheral joints of active ankylosing spondylitis. Scand J Rheumatol. 2008; 37:1-8. [PubMed: 18189187]

Dougados M, Baeten D. Spondyloarthritis. Lancet. 2011; 377:2127-2137. [PubMed: 21684383]

Edwards JCW, Bowness P, Archer JR. Jekyll and Hyde: the transformation of HLA-B27. Immunol Today. 2000; 21:256-260. [PubMed: 10825736]

Ellgaard L, Helenius A. Quality control in the endoplasmic reticulum. Nature Rev Mol Cell Biol. 2003; 4:181-191. [PubMed: 12612637]

Evans DM, Spencer CC, Pointon JJ, Su Z, Harvey D, Kochan G, Oppermann U, Dilthey A, Pirinen M, Stone MA, et al. Interaction between ERAP1 and HLA-B27 in ankylosing spondylitis implicates peptide handling in the mechanism for HLA-B27 in disease susceptibility. Nat Genet. 2011; 43:761-767. [PubMed: 21743469]

Feng Y, Ding J, Fan CM, Zhu P. Interferon-gamma contributes to HLA-B27-associated unfolded protein response in spondyloarthropathies. J Rheumatol. 2012; 39:574-582. [PubMed: 22247344]

Fussell H, Nesbeth D, Lenart I, Campbell EC, Lynch S, Santos S, Gould K, Powis SJ, Antoniou AN. Novel detection of in vivo HLA-B27 conformations correlates with ankylosing spondylitis association. Arthritis Rheum. 2008; 58:3419-3424. [PubMed: 18975339]

Goodall JC, Wu C, Zhang Y, McNeill L, Ellis L, Saudek V, Gaston JS. Endoplasmic reticulum stressinduced transcription factor, CHOP, is crucial for dendritic cell IL-23 expression. Proceedings of the National Academy of Sciences of the United States of America. 2010; 107:17698-17703. [PubMed: 20876114]

Gregersen N, Bross P. Protein misfolding and cellular stress: an overview. Methods in molecular biology. 2010; 648:3-23. [PubMed: 20700702]

Gu J, Rihl M, Marker-Hermann E, Baeten D, Kuipers JG, Song YW, Maksymowych WP, BurgosVargas R, Veys EM, De Keyser F, et al. Clues to the pathogenesis of spondyloarthropathy derived from synovial fluid mononuclear cell gene expression profiles. J Rheumatol. 2002; 29:2159-2164. [PubMed: 12375327]

Hammer RE, Maika SD, Richardson JA, Tang JP, Taurog JD. Spontaneous inflammatory disease in transgenic rats expressing HLA-B27 and human $\beta_{2}$-m: an animal model of HLA-B27-associated human disorders. Cell. 1990; 63:1099-1112. [PubMed: 2257626]

Helmick CG, Felson DT, Lawrence RC, Gabriel S, Hirsch R, Kwoh CK, Liang MH, Kremers HM, Mayes MD, Merkel PA, et al. Estimates of the prevalence of arthritis and other rheumatic conditions in the United States. Part I. Arthritis Rheum. 2008; 58:15-25. [PubMed: 18163481]

Hetz C, Thielen P, Matus S, Nassif M, Court F, Kiffin R, Martinez G, Cuervo AM, Brown RH, Glimcher LH. XBP-1 deficiency in the nervous system protects against amyotrophic lateral sclerosis by increasing autophagy. Genes \& development. 2009; 23:2294-2306. [PubMed: 19762508]

Hou FF, Miyata T, Boyce J, Yuan Q, Chertow GM, Kay J, Schmidt AM, Owen WF. beta(2)Microglobulin modified with advanced glycation end products delays monocyte apoptosis. Kidney Int. 2001; 59:990-1002. [PubMed: 11231354]

Hughes EA, Hammond C, Cresswell P. Misfolded major histocompatibility complex class I heavy chains are translocated into the cytoplasm and degraded by the proteasome. Proc Natl Acad Sci USA. 1997; 94:1896-1901. [PubMed: 9050876]

Iwakoshi NN, Pypaert M, Glimcher LH. The transcription factor XBP-1 is essential for the development and survival of dendritic cells. J Exp Med. 2007; 204:2267-2275. [PubMed: 17875675]

Jaakkola E, Herzberg I, Laiho K, Barnardo MC, Pointon JJ, Kauppi M, Kaarela K, Tuomilehto-Wolf E, Tuomilehto J, Wordsworth BP, et al. Finnish HLA studies confirm the increased risk conferred by HLA-B27 homozygosity in ankylosing spondylitis. Ann Rheum Dis. 2006; 65:775-780. [PubMed: 16249228]

Jacques P, Van Praet L, Carron P, Van den Bosch F, Elewaut D. Pathophysiology and role of the gastrointestinal system in spondyloarthritides. Rheum Dis Clin North Am. 2012; 38:569-582. [PubMed: 23083756] 
Jardetzky TS, Lane WS, Robinson RA, Madden DR, Wiley DC. Identification of self peptides bound to purified HLA-B27. Nature. 1991; 353:326-329. [PubMed: 1922338]

Kenna TJ, Davidson SI, Duan R, Bradbury LA, McFarlane J, Smith M, Weedon H, Street S, Thomas R, Thomas GP, et al. Enrichment of circulating interleukin-17-secreting interleukin-23 receptorpositive gamma/delta $\mathrm{T}$ cells in patients with active ankylosing spondylitis. Arthritis Rheum. 2012; 64:1420-1429. [PubMed: 22144400]

Kollnberger S, Bird LA, Sunm MY, Retiere C, Braud VM, McMichael A, Bowness P. Cell surface expression and immune receptor recogntion of HLA-B27 homodimers. Arthritis Rheum. 2002; 46:2972-2982. [PubMed: 12428240]

Kroemer G, Marino G, Levine B. Autophagy and the integrated stress response. Mol Cell. 2010; 40:280-293. [PubMed: 20965422]

Kundu M, Thompson CB. Autophagy: basic principles and relevance to disease. Annual review of pathology. 2008; 3:427-455.

Layh-Schmitt G, Colbert RA. The interleukin-23/interleukin-17 axis in spondyloarthritis. Curr Opin Rheumatol. 2008; 20:392-397. [PubMed: 18525350]

Layh-Schmitt G, Yang EY, Kwon G, Colbert RA. HLA-B27 alters the response to TNFalpha and promotes osteoclastogenesis in bone marrow monocytes from HLA-B27 transgenic rats. Arthritis Rheum. 2013

Lenart I, Guiliano DB, Burn G, Campbell EC, Morley KD, Fussell H, Powis SJ, Antoniou AN. The MHC Class I heavy chain structurally conserved cysteines 101 and 164 participate in HLA-B27 dimer formation. Antioxidants \& redox signaling. 2012; 16:33-43. [PubMed: 21902594]

Madden DR, Garboczi DN, Wiley DC. The antigenic identity of peptide-MHC complexes: A comparison of the conformations of five viral peptides presented by HLA-A2. Cell. 1993; 75:693708. [PubMed: 7694806]

Martinon F, Chen X, Lee AH, Glimcher LH. TLR activation of the transcription factor XBP1 regulates innate immune responses in macrophages. Nat Immunol. 2010; 11:411-418. [PubMed: 20351694]

Mear JP, Schreiber KL, Munz C, Zhu X, Stevanovic S, Rammensee HG, Rowland-Jones SL, Colbert RA. Misfolding of HLA-B27 as a result of its B pocket suggests a novel mechanism for its role in susceptibility to spondyloarthropathies. J Immunol. 1999; 163:6665-6670. [PubMed: 10586062]

Miyata T, Hori O, Zhang J, Yan SD, Ferran L, Iida Y, Schmidt AM. The receptor for advanced glycation end products (RAGE) is a central mediator of the interaction of AGE-

beta2microglobulin with human mononuclear phagocytes via an oxidant-sensitive pathway. Implications for the pathogenesis of dialysis-related amyloidosis. J Clin Invest. 1996; 98:10881094. [PubMed: 8787669]

Molinari M, Galli C, Piccaluga V, Pieren M, Paganetti P. Sequential assistance of molecular chaperones and transient formation of covalent complexes during protein degradation from the ER. J Cell Biol. 2002; 158:247-257. [PubMed: 12119363]

Molinari M, Galli C, Vanoni O, Arnold SM, Kaufman RJ. Persistent glycoprotein misfolding activates the glucosidase II/UGT1-driven calnexin cycle to delay aggregation and loss of folding competence. Mol Cell. 2005; 20:503-512. [PubMed: 16307915]

Noessner E, Parham P. Species-specific differences in chaperone interaction of human and mouse major histocompatibility complex class I molecules. J Exp Med. 1995; 181:327-337. [PubMed: 7807012]

Ogata M, Hino S, Saito A, Morikawa K, Kondo S, Kanemoto S, Murakami T, Taniguchi M, Tanii I, Yoshinaga K, et al. Autophagy is activated for cell survival after endoplasmic reticulum stress. Molecular and cellular biology. 2006; 26:9220-9231. [PubMed: 17030611]

Peral de Castro C, Jones SA, Ni Cheallaigh C, Hearnden CA, Williams L, Winter J, Lavelle EC, Mills $\mathrm{KH}$, Harris J. Autophagy regulates IL-23 secretion and innate T cell responses through effects on IL-1 secretion. J Immunol. 2012; 189:4144-4153. [PubMed: 22972933]

Reveille JD. Genetics of spondyloarthritis--beyond the MHC. Nature reviews Rheumatology. 2012; 8:296-304.

Reveille JD, Sims AM, Danoy P, Evans DM, Leo P, Pointon JJ, Jin R, Zhou X, Bradbury LA, Appleton LH, et al. Genome-wide association study of ankylosing spondylitis identifies non-MHC susceptibility loci. Nat Genet. 2010; 42:123-127. [PubMed: 20062062] 
Rouschop KM, van den Beucken T, Dubois L, Niessen H, Bussink J, Savelkouls K, Keulers T, Mujcic $\mathrm{H}$, Landuyt W, Voncken JW, et al. The unfolded protein response protects human tumor cells during hypoxia through regulation of the autophagy genes MAP1LC3B and ATG5. J Clin Invest. 2010; 120:127-141. [PubMed: 20038797]

Schmidt AM, Yan SD, Yan SF, Stern DM. The multiligand receptor RAGE as a progression factor amplifying immune and inflammatory responses. J Clin Invest. 2001; 108:949-955. [PubMed: 11581294]

Shen H, Goodall JC, Hill Gaston JS. Frequency and phenotype of peripheral blood Th17 cells in ankylosing spondylitis and rheumatoid arthritis. Arthritis Rheum. 2009; 60:1647-1656. [PubMed: 19479869]

Sherlock JP, Joyce-Shaikh B, Turner SP, Chao CC, Sathe M, Grein J, Gorman DM, Bowman EP, McClanahan TK, Yearley JH, et al. IL-23 induces spondyloarthropathy by acting on ROR-gammat + CD3+CD4-CD8- entheseal resident T cells. Nat Med. 2012; 18:1069-1076. [PubMed: 22772566]

Smith JA, Barnes MD, Hong D, DeLay ML, Inman RD, Colbert RA. Gene expression analysis of macrophages derived from ankylosing spondylitis patients reveals interferon-gamma dysregulation. Arthritis Rheum. 2008a; 58:1640-1649. [PubMed: 18512784]

Smith JA, Turner MJ, DeLay ML, Klenk EI, Sowders DP, Colbert RA. Endoplasmic reticulum stress and the unfolded protein response are linked to synergistic IFN-beta induction via X-box binding protein 1. Eur J Immunol. 2008b; 38:1194-1203. [PubMed: 18412159]

Song IH, Maksymowych WP. Therapeutic controversies: tumor necrosis factor alpha inhibitors in ankylosing spondylitis. Rheum Dis Clin North Am. 2012; 38:613-633. [PubMed: 23083759]

Stam NJ, Spits H, Ploegh HL. Monoclonal antibodies raised against denatured HLA-B locus H-chains permit biochemical characterization of certain HLA-C locus products. J Immunol. 1986; 137:2299-2306. [PubMed: 3760563]

Takayanagi H, Kim S, Matsuo K, Suzuki H, Suzuki T, Sato K, Yokochi T, Oda H, Nakamura K, Ida $\mathrm{N}$, et al. RANKL maintains bone homeostasis through c-Fos-dependent induction of interferonbeta. Nature. 2002; 416:744-749. [PubMed: 11961557]

Taurog JD, Maika SD, Satumtira N, Dorris ML, McLean IL, Yanagisawa H, Sayad A, Stagg AJ, Fox GM, O'Brien AL, et al. Inflammatory disease in HLA-B27 transgenic rats. Immunol Rev. 1999; 169:209-223. [PubMed: 10450519]

Taurog JD, Maika SD, Simmons WA, Breban M, Hammer RE. Susceptibility to inflammatory disease in HLA-B27 transgenic rat lines correlates with the level of B27 expression. J Immunol. 1993; 150:4168-4178. [PubMed: 8473755]

Tran TM, Dorris ML, Satumtira N, Richardson JA, Hammer RE, Shang J, Taurog JD. Additional human beta(2)-microglobulin curbs HLA-B27 misfolding and promotes arthritis and spondylitis without colitis in male HLA-B27-transgenic rats. Arthritis Rheum. 2006; 54:1317-1327. [PubMed: 16575857]

Tran TM, Satumtira N, Dorris ML, May E, Wang A, Furuta E, Taurog JD. HLA-B27 in transgenic rats forms disulfide-linked heavy chain oligomers and multimers that bind to the chaperone BiP. J Immunol. 2004; 172:5110-5119. [PubMed: 15067095]

Turner MJ, Delay ML, Bai S, Klenk E, Colbert RA. HLA-B27 up-regulation causes accumulation of misfolded heavy chains and correlates with the magnitude of the unfolded protein response in transgenic rats: Implications for the pathogenesis of spondylarthritis-like disease. Arthritis Rheum. 2007; 56:215-223. [PubMed: 17195225]

Turner MJ, Sowders DP, DeLay ML, Mohapatra R, Bai S, Smith JA, Brandewie JR, Taurog JD, Colbert RA. HLA-B27 misfolding in transgenic rats is associated with activation of the unfolded protein response. J Immunol. 2005; 175:2438-2448. [PubMed: 16081815]

Vidal RL, Hetz C. Unspliced XBP1 controls autophagy through FoxO1. Cell research. 2013; 23:463464. [PubMed: 23337584]

Wendling D, Cedoz JP, Racadot E, Dumoulin G. Serum IL-17, BMP-7, and bone turnover markers in patients with ankylosing spondylitis. Joint Bone Spine. 2007; 74:304-305. [PubMed: 17369068] 
Yarilina A, Park-Min KH, Antoniv T, Hu X, Ivashkiv LB. TNF activates an IRF1-dependent autocrine loop leading to sustained expression of chemokines and STAT1-dependent type I interferonresponse genes. Nat Immunol. 2008; 9:378-387. [PubMed: 18345002]

Zeng L, Lindstrom MJ, Smith JA. Ankylosing spondylitis macrophage production of higher levels of interleukin-23 in response to lipopolysaccharide without induction of a significant unfolded protein response. Arthritis Rheum. 2011; 63:3807-3817. [PubMed: 22127699]

Zeng L, Liu YP, Sha H, Chen H, Qi L, Smith JA. XBP-1 couples endoplasmic reticulum stress to augmented IFN-beta induction via a cis-acting enhancer in macrophages. J Immunol. 2010; 185:2324-2330. [PubMed: 20660350]

Zhao Y, Li X, Cai MY, Ma K, Yang J, Zhou J, Fu W, Wei FZ, Wang L, Xie D, et al. XBP-1u suppresses autophagy by promoting the degradation of FoxO1 in cancer cells. Cell research. 2013; 23:491-507. [PubMed: 23277279] 


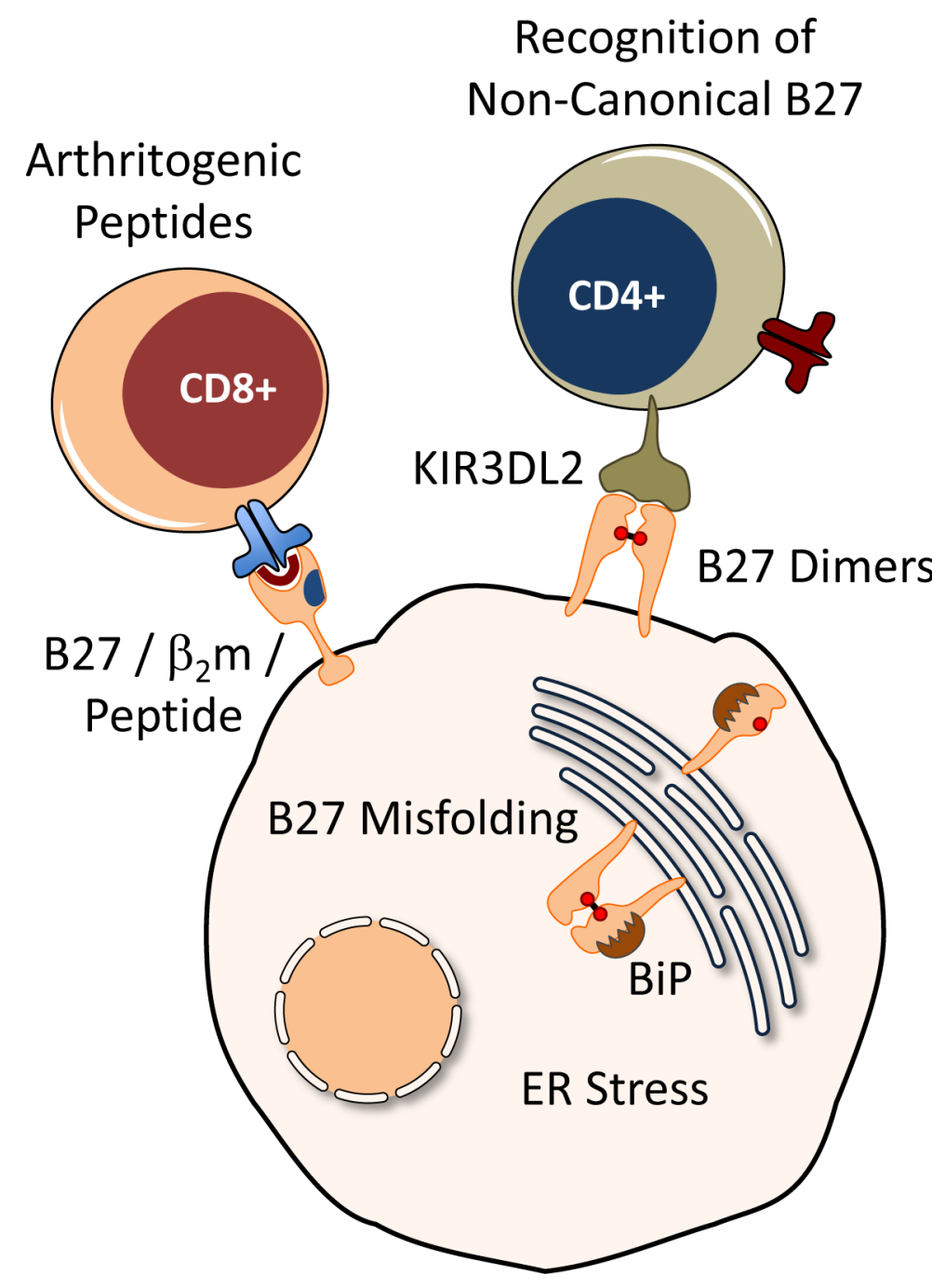

Figure 1.

Current hypotheses linking HLA-B27 to spondyloarthritis pathogenesis. (1) Arthritogenic Peptides: Self peptides selected and presented by properly folded forms of HLA-B27 complexed with $\beta_{2} \mathrm{~m}$ have been hypothesized to be the target of autoreactive CD8+ T cells, and serve as an upstream initiator of inflammation. (2) Recognition of Non-Canonical HLA-B27: Naturally occurring cell surface HLA-B27 dimers are hypothesized to be recognized by killer immunoglobulin receptors (such as KIR3DL2) in the leukocyte immunoglobulin-like receptor family (LILR), and trigger inflammation. (3) HLA-B27 Misfolding: The formation of misfolded oligomers and BiP binding by newly synthesized HLA-B27 heavy chains causes ER stress, which has intrinsic effects on cellular function that are hypothesized to promote development of spondyloarthritis. HLA-B27 can exhibit all three of these behaviors in the same cell, and these concepts are not mutually exclusive. 


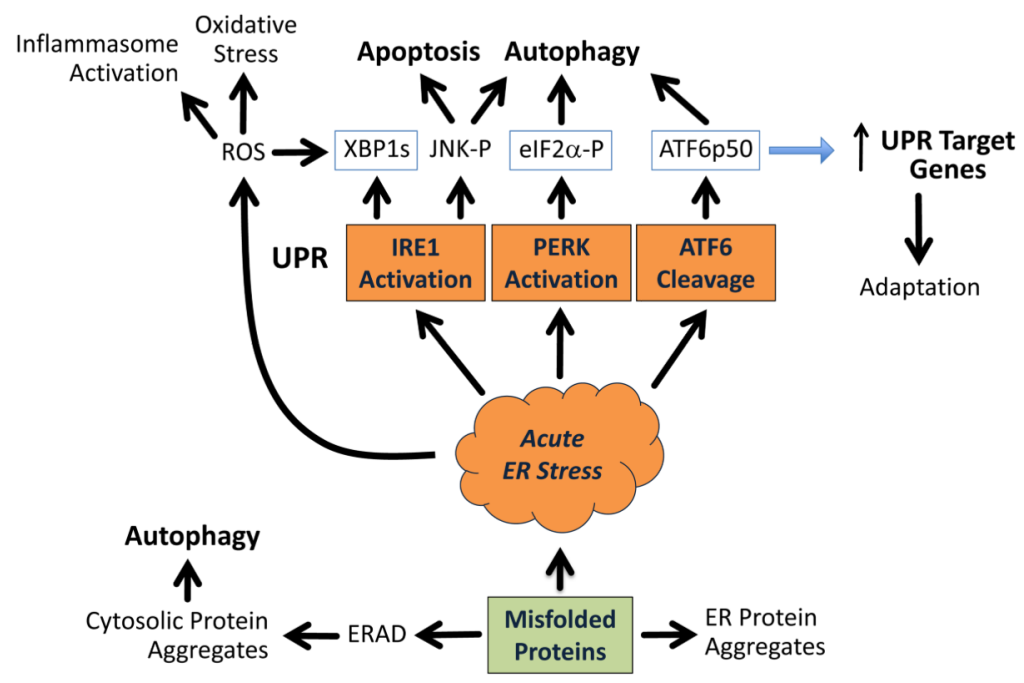

Figure 2.

Consequences of ER protein misfolding. Misfolded ER proteins may be eliminated by ERAD, which involves dislocation from the ER to the cytosol, ubiquitination, and proteasomal degradation. Autophagy contributes to the elimination of aberrant proteins, particularly when ERAD is insufficient or when cytosolic proteins aggregate. ER protein aggregates that do not activate stress response pathways can contribute to cellular dysfunction. An acute ER stress response may be signaled when misfolded or unfolded proteins sequester BiP, thus allowing activation of IRE1, PERK and ATF6. XBP1s and ATF6p50 are active transcription factors, and eIF2a phosphorylation $(\mathrm{P})$ results in translational induction of ATF4 and CHOP, two additional UPR transcription factors, that together orchestrate transcriptional changes that enhance the cell's ability to fold and secrete proteins, thus reducing ER stress. Transcriptional changes subside after a successful UPR, resulting in adaptation, which may alter the threshold for a subsequent ER stress response. 


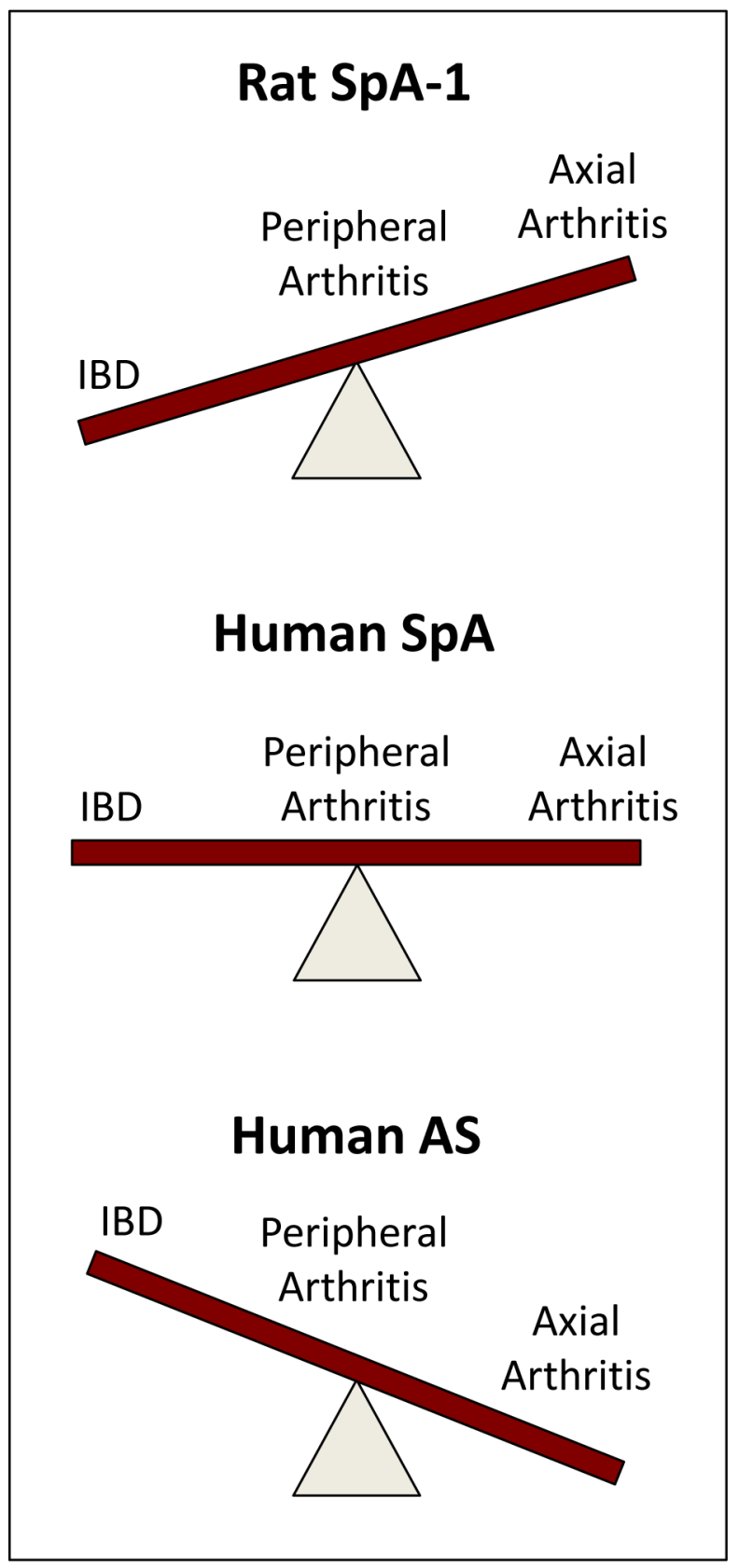

Figure 3.

Comparison of the principle phenotypic features of rat and human spondyloarthritis. Rats with 20-40 or more copies of the HLA-B27 transgene in the presence of 15-30 copies of $\mathrm{h} \beta_{2} \mathrm{~m}$ develop spondyloarthritis-like inflammatory disease spontaneously, beginning shortly after weaning. IBD develops in virtually $100 \%$ of HLA-B27 transgenic rats, while peripheral and axial arthritis occur with significantly reduced frequency, and generally after several months of age (Rat SpA-1). Human spondyloarthritis (undifferentiated spondyloarthritis classified various ways) exhibits a more equal mix of IBD (Crohn's disease and ulcerative colitis), and peripheral and axial arthritis. Psoriatic arthritis and psoriatic spondylitis are not represented here. Nevertheless, development of skin and nail changes have been reported in HLA-B27 transgenic rats and psoriatic skin lesions occur in 
IL-23 overexpressing mice. Human AS represents the other end of the spectrum where axial arthritis in the form of radiographic sacroiliitis occurs in 100\% of affected individuals (by definition), and peripheral arthritis and overt IBD are significantly less frequent. However, sub-clinical IBD occurs in close to $70 \%$ of individuals with AS, with overt IBD in $\sim 6 \%$. A second rat spondyloarthritis model (SpA-2; not shown) occurs with forced overexpression of additional $\mathrm{h}{ }_{2} \mathrm{~m}$ (35 transgene copies) in rats with 20 or more copies of HLA-B27 and at least 50 copies of $\mathrm{h} \beta_{2} \mathrm{~m}$. Rat $\mathrm{SpA}-2$ does not require IBD, although this phenotypic feature still occurs in high copy HLA-B27 transgenic rats with additional $\mathrm{h} \beta_{2} \mathrm{~m}$. Both peripheral and axial arthritis occur at much higher frequency and severity with additional $\mathrm{h} \beta_{2} \mathrm{~m}$, but arthritis is primarily restricted to male rats and requires epididymoorchitis. 